\title{
Intervenção local com crianças e famílias face à pandemia COVID-19: ProChild CoLAB em Guimarães
}

\author{
https://doi.org/10.21814/uminho.ed.24.4
}

\section{Manuel Jacinto Sarmento}

Manuel Jacinto Sarmento (ORCID: 0000-0002-6556-9498) é Professor Associado do Instituto de Educação e membro do Centro de Investigação de Educação (CIEC) da Universidade do Minho.

\section{Gabriela Trevisan}

Gabriela Trevisan (ORCID: 0000-0002-0039-931X) é socióloga e investigadora do ProChild CoLAB.

\section{Helena Grangeia}

Helena Grangeia (ORCID: 0000-0002-5521-8352) é psicóloga e investigadora do ProChild CoLAB.

\section{Marlene Sousa}

Marlene Sousa (ORCID: 0000-0003-2991-3017) é psicóloga e investigadora do ProChild CoLAB.

\section{Inês Guedes de Oliveira}

Inês Guedes de Oliveira (ORCID: 0000-0003-2359-7842) é Professora Auxiliar do Departamento de Comunicação e Arte da Universidade de Aveiro. 


\section{Adelina Paula Pinto}

Adelina Paula Pinto é Vice-Presidente da Câmara Municipal de Guimarães.

\section{Adriana Sampaio}

Adriana Sampaio (ORCID: 0000-0001-7347-1282) é Professora Auxiliar e Vice-Presidente da Escola de Psicologia e membro do Centro de Investigação em Psicologia (CIPsi) da Universidade do Minho.

\section{Bárbara Figueiredo}

Bárbara Figueiredo (ORCID: 0000-0002-8209-7445) é Professora Associada com agregação Escola de Psicologia e Diretora do Centro de Investigação em Psicologia (CIPsi) da Universidade do Minho.

\section{Gabriela Bento}

Gabriela Bento (ORCID: 0000-0003-4113-5692) é psicóloga e investigadora do ProChild CoLAB.

\section{Mariana Carvalho}

Mariana Carvalho (ORCID: 0000-0003-0075-5000) é arquiteta e investigadora do ProChild CoLAB.

\section{Teresa Freire}

Teresa Freire (ORCID: 0000-0001-5773-381X) é Professora Auxiliar da Escola de Psicologia e membro do Centro de Investigação em Psicologia (CIPsi) da Universidade do Minho. 


\section{Marlene Matos}

Marlene Matos (ORCID: 0000-0002-2194-839X) é Professora Auxiliar da Escola de Psicologia e membro do Centro de Investigação em Psicologia (CIPsi) da Universidade do Minho.

\section{Isabel Soares}

Isabel Soares (ORCID: 0000-0002-2707-7089) é Professora Catedrática da Escola de Psicologia e membro do Centro de Investigação em Psicologia (CIPsi) da Universidade do Minho. 


\section{INTRODUÇÃO}

A pandemia COVID-19 desenvolveu-se em Portugal, a partir de março de 2019, de forma acelerada, obrigando a adaptaçóes muito rápidas das entidades públicas, dos serviços, das empresas e dos/as cidadãos/ãs, com vista a conter os seus efeitos sanitários, sociais e económicos. A incerteza que carateriza a sociedade contemporânea, em muitos dos seus domínios e setores, apresentou-se, desta vez, sob a forma microscópica de um vírus, capaz de, por si só, obrigar à alteração, com caráter de urgência, de hábitos consolidados, formas de sociabilidade ancestrais, planos e projetos de existência maduramente estabelecidos.

Todos os setores da sociedade foram atingidos pela pandemia. No entanto, foram-no de forma distinta, em função das condições de desigualdade e de diversidade da estrutura social. Também essas diferenças se manifestaram no que respeita às gerações e etapas da vida. $\mathrm{O}$ vírus ataca de forma e com efeitos diferenciados as pessoas idosas, as pessoas adultas e as crianças. No caso da geração mais jovem, o impacto da pandemia manifestou-se a vários níveis: os quotidianos escolares foram substituídos por aprendizagens realizadas no espaço doméstico, com apoio televisivo e das ferramentas informáticas; o convívio familiar rotineiro ampliou-se em cada 24 horas, pela presença dos/as pais/mães no horário de trabalho, em situação de teletrabalho, de lay-off ou desemprego; a relação intergeracional com avôs/avós e parentes mais velhos/as viu-se subitamente interrompida, sob a ameaça da contaminação; a confraternização e a brincadeira entre pares deu lugar ao isolamento e à solidão, ou a interações visuais pelo telemóvel ou nas redes sociais; o espaço público foi condicionado em período de confinamento e não só os parques infantis foram encerrados, como a invisibilidade social das crianças ganhou uma expressão direta no esvaziamento das cidades, de repente despojadas dos seus munícipes mais jovens; algumas crianças, em situação de maior vulnerabilidade, sofreram diretamente os efeitos psicológicos, sociais e económicos da pandemia: tornaram-se mais expostas aos impactos na saúde mental das respetivas famílias, perderam, nalguns casos, o contacto com os/as professores/as e as escolas, nomeadamente pelo facto de não possuírem meios eletrónicos de contacto e sofreram carências alimentares por empobrecimento dos/as pais/mães. 
Rapidamente, um conjunto de relatórios de grandes agências internacionais sinalizou os riscos e os perigos para as crianças e jovens face à pandemia COVID-19 e assinalou a imperatividade de medidas capazes de minimizar e contrariar os respetivos fatores (e.g., Alliance for Child Protection in Humanitarian Action, 2019; Bakrania \& Subrahmanian, 2020; Reimers \& Schleicher, 2020; International Commission on the Futures of Education, 2020). O conjunto dessas medidas apresenta alguns pontos comuns: devem ser adotadas medidas com urgência e acuidade; é fundamental que os seus contextos de aplicação sejam devidamente identificados, o que exige proximidade; é necessário que as açốes sejam diversificadas, para atender à diversidade de situaçóes, mas devidamente articuladas, de acordo com o princípio de diversificar com coerência; devem ser devidamente integradas e coordenadas; devem sustentar-se numa ética do cuidado, que é, também, a base de uma "economia do cuidado" (Reis, 2020); por último, devem basear-se no conhecimento científico e devem ser devidamente monitorizadas e avaliadas.

Todos estes aspetos - acuidade, proximidade, diversidade com coerência, integração, ética do cuidado, fundamento científico - constituem a base de modelos de ação que assumem a criança como centro da intervenção, com a preocupação da promoção do seu desenvolvimento e bem-estar, na perspetiva da garantia dos seus direitos.

Foi um modelo também assente nestes princípios aquele que se desenvolveu na intervenção com crianças face à pandemia COVID-19 no município de Guimarães, a partir da Câmara Municipal, em parceria com o ProChild CoLAB.

O ProChild CoLAB é o laboratório colaborativo que tem por missão o combate à pobreza e à exclusão social na infância, enquadrado numa abordagem científica transdisciplinar que articula os setores público e privado. Constituído a partir da iniciativa da Universidade do Minho, conta como associadas as principais universidades portuguesas, empresas de referência nacional, a Santa Casa da Misericórdia de Lisboa e o Município de Guimarães.

O modelo integrado de intervenção nas crianças e famílias foi desenhado pelo ProChild CoLAB em estreita relação com a Câmara Municipal de Guimarães e constitui o programa de intervenção específica, articulando-se com outras açôes do Município dirigidas para outros setores populacionais (designadamente para as pessoas idosas) 
e para outros âmbitos de ação (nomeadamente a economia), bem como com as ações promovidas pelas autoridades e agentes locais de saúde. Este modelo é também complementar de medidas adotadas pelo município na resposta a necessidades identificadas nas crianças no que respeita, designadamente, à distribuição de alimentos, ao fornecimento de computadores e disponibilização de acesso à internet e ao apoio e acompanhamento social das famílias.

No seu conjunto, o modelo procurou dar resposta às necessidades identificadas, nomeadamente no que respeita aos efeitos da pandemia na saúde mental das crianças, às necessidades educativas das crianças, ao acompanhamento do desenvolvimento, à promoção da parentalidade positiva e à promoção da ludicidade, no quadro de criação de condições de bem-estar pessoal e social.

De seguida apresentar-se-ão os fundamentos do modelo, as suas especificações e as suas concretizações em projetos da intervenção realizada.

\section{FUNDAMENTOS DO MODELO DE INTERVENÇÃO}

Um princípio base e transversal a todos os projetos do ProChild CoLAB é o desenvolvimento de respostas integradas e apoiadas na evidência científica, envolvendo a colaboração e articulação intersectorial entre a equipa de profissionais e os vários serviços de apoio à infância e às famílias na comunidade.

$\mathrm{Na}$ fase de caracterização do território do Município de Guimarães e de auscultação dos/as profissionais das diferentes instituições (finais de 2019 e início de 2020), ficaram patentes diversas necessidades e dificuldades, entre as quais se salientam as relacionadas com a articulação de respostas e com a provisão de práticas que se sustentem em conhecimento empiricamente validado. Da mesma forma, foi salientada a importância de uma ação concertada, interdisciplinar e colaborativa entre os/as diferentes profissionais para a obtenção de resultados positivos e duradouros. Tornou-se evidente a importância do ProChild CoLAB assumir um papel catalisador e mediador entre os/as profissionais do Município de Guimarães, dando resposta às necessidades elencadas pelos/as mesmos/as. 
Assim, no âmbito da sua atuaçãa, o ProChild CoLAB propôs-se desenvolver um modelo colaborativo, intersectorial e multinível de formação de profissionais para uma intervenção centrada na criança e nos seus contextos de vida (as intervenções concretas serão apresentadas no ponto 4 deste texto). Este projeto abrange todo o território do Município de Guimarães e integra profissionais de diferentes áreas que, na sua prática, atuam ao nível dos contextos de saúde, educação e proteção. O objetivo é melhorar as práticas e políticas do município, introduzindo modelos empiricamente validados, não só ao nível da intervenção junto das crianças e famílias, mas também ao nível da atuação dos/as próprios/as profissionais.

Este projeto baseia-se em modelos com evidência empírica da sua eficácia, fundamentando-se:

(1) numa estratégia de implementação assente numa abordagem colaborativa e multinível;

(2) no modelo Exploration, Preparation, Implementation and Sustainment (Aarons, Hurlburt, \& Horwitz, 2011) que orienta as fases de operacionalização e de manutenção;

(3) nos princípios do modelo IDEAS Impact Framework (Center on Developing Child, Universidade de Harvard) para a sua avaliação.

Este projeto tem, assim, como missão primordial desenvolver, implementar e avaliar um modelo colaborativo, multinível e intersectorial de formação de profissionais para uma intervenção centrada na criança e na família a partir de práticas baseadas na evidência empírica. Especificamente, este projeto procura:

(1) colmatar a lacuna existente ao nível da relação entre a ciência e a prática;

(2) promover a adesão às práticas baseadas na evidência científica, bem como a sua sustentabilidade;

(3) e fomentar o trabalho colaborativo e intersectorial entre profissionais, entidades e contextos comunitários, da saúde, da educação e da proteção à criança. 
Neste sentido, este projeto visa assegurar não só a qualificação dos/as profissionais/atores sociais ao nível das práticas e modelos cientificamente válidos e eficazes, mas também as condições intra e intersectoriais para a sua implementação, cumprindo com os critérios de fidelidade, sustentabilidade e escala (Walsh, Rolls, Reutz, \& Williams, 2015).

Os seus objetivos não se esgotam, porém, nos/as profissionais, mas estendem-se às crianças, famílias e instituiçôes do município. Com este modelo procura-se promover e agilizar, ao nível das crianças e respetivas famílias, o acesso a intervenções eficazes e adequadas às suas especificidades e necessidades, fomentando o seu bem-estar físico, psicológico e socioemocional. Ao nível das instituiçóes, procura-se melhorar as suas práticas, tornando-as mais céleres e eficazes, potenciando os seus recursos. Por fim, ao nível do município tem como objetivo delinear uma ação concertada e empiricamente sustentada, melhorando as práticas relativas à intervenção na infância.

No contexto da pandemia COVID-19, considerando os princípios enunciados, e com o objetivo de promover e assegurar a saúde, bem-estar, educação e proteção das crianças, foi desenvolvido o projeto "ProChild Collaborative Action Against COVID-19”. Assente nos princípios de uma intervenção comunitária colaborativa, intersectorial e multinível, este projeto procura dar resposta às múltiplas necessidades e desafios que crianças e famílias enfrentam neste período pandémico. E que necessidades e desafios são esses?

\section{IMPACTO DA PANDEMIA COVID-19 NAS CRIANÇAS E FAMÍLIAS}

A pandemia COVID-19 está a ter implicaçôes sociais e económicas significativas, que se repercutem no modo de vida de crianças, famílias e suas comunidades. Estes efeitos apresentam uma natureza desigualitária, não democrática, afetando particularmente indivíduos com vínculos laborais precários, com menor escolarização e ligados a ramos profissionais particularmente afetados pelas mudanças trazidas pela pandemia, como o turismo, a hotelaria e a restauração (Silva et al., 2020). De acordo com Rodrigues (2020), a pandemia COVID-19 acentuou desigualdades existentes (e.g., famílias dependentes do trabalho informal ficaram sem rendimentos e sem acesso a proteção social), fez emergir novas formas de desigualdade (e.g., a ligação de algumas crianças 
ao sistema de ensino degradou-se e a capacidade de acompanhamento online dos conteúdos escolares mostrou-se muito dependente das condiçóes sociais dos/as alunos/as) e enfraqueceu mecanismos de proteção e de combate às desigualdades (e.g., o encerramento das cantinas escolares impossibilitou o acesso a refeiçóes gratuitas por parte de crianças que beneficiavam deste apoio; “confinaram-se” situações de violência doméstica, que não foram reportadas aos serviços de proteção).

Paralelamente, surgem desafios sem precedentes no campo da saúde pública, nomeadamente que se refere à vigilância e mitigação dos impactos adversos e potencialmente traumáticos da pandemia nos indivíduos, famílias e comunidades. Apesar de a maioria dos indivíduos poder não desenvolver uma resposta traumática face ao cenário atual de adversidade, está já demonstrado que a perda, o medo e o stress, fortemente associados à COVID-19, exacerbam problemas de saúde mental já existentes e contribuem para uma maior incidência de perturbações relacionadas com o stress e o trauma (Qiu et al., 2020). Enquanto fator de stress, o atual cenário de pandemia apresenta características que acentuam a sua natureza traumática, nomeadamente a indefinição sobre a evolução e o limite temporal da pandemia, a mortalidade associada à infeção, a extensa cobertura mediática, o isolamento social, as perdas financeiras e/ou a potenciação das vulnerabilidades sociais (Horesh \& Brown, 2020). A figura 1 esquematiza alguns dos efeitos da pandemia COVID-19 nos indivíduos, famílias, comunidade e sociedade.

No cenário atual de pandemia, as crianças destacam-se como um grupo de risco no que respeita aos efeitos adversos na saúde mental (Qiu et al., 2020). A pandemia altera drasticamente os contextos de vida da criança, aumentando o risco ou agravando situações já existentes de desproteção nos contextos socioeconómicos, familiares ou de acolhimento (Sistovaris et al., 2020). 


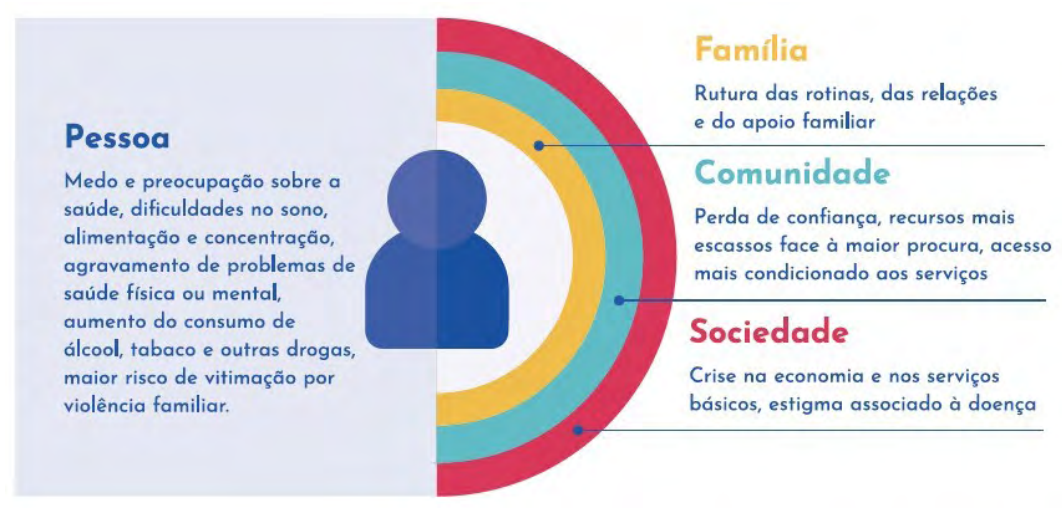

Figura 1. Impacto socioecológico da pandemia COVID-19 (adaptado a partir do esquema da Alliance for Child Protection in Humanitarian Action, 2019, p. 2).

Destacam-se os efeitos das medidas de confinamento na saúde física (e.g., desregulação de padróes de sono, exercício físico e alimentação) e mental das crianças que, associados à sua duração prolongada, ao medo da doença, à informação inadequada ou alarmista, ao espaço limitado, à disfunção e stressores familiares (Liu, Bao, Huang, Shi, \& lu, 2020; Wang, Zhang, Zhao, \& Zhang, 2020), aumentam a incidência de perturbações associadas ao stress e trauma (Sprang \& Silman, 2013). O afastamento do meio escolar contribuiu para o surgimento de sentimentos de solidão, tristeza e frustração por parte das crianças, que se viram privadas de interaçóes presenciais com os pares e com os/as professores/as e de momentos lúdicos nos recreios, centrais para o seu desenvolvimento e bem-estar. Os resultados preliminares de um estudo transnacional coordenado pela Faculdade de Psicologia da Universidade de Lisboa e ProChild CoLAB corroboram este impacto ao nível de indicadores clínicos de ansiedade nas crianças portuguesas em período de pandemia, apontando para 11.3\% numa amostra de 565 crianças entre os 6 e os 16 anos.

"Estar na escola” passou a significar estar muitas horas em frente a ecrãs, sendo que este formato online trouxe problemas significativos para muitas crianças, que se viram afastadas de qualquer hipótese de contacto com os pares e com os professores. A carência de meios informáticos e de ligação à internet em muitos agregados familiares impossibilitou a comunicação e acentuou a desigualdade no acesso a oportunidades de aprendizagem de qualidade. O sucesso do ensino à distância viu-se refém de uma 
multiplicidade de fatores extra escola (e.g., disponibilidade dos/as pais/mães; equipamentos existentes) que, apesar dos esforços das autarquias, das escolas e dos/as professores/as, não foram completamente superados.

Além disso, o confinamento contribuiu para o surgimento ou agravamento de fatores de risco para os maus-tratos às crianças. $\mathrm{Na}$ ausência de apoio formal e informal, as famílias procuram dar resposta, num mesmo espaço e tempo, às responsabilidades inerentes ao trabalho pago, ao cuidado e à educação das crianças e às tarefas domésticas (Alliance for Child Protection in Humanitarian Action, 2019; UNICEF, 2020). Esta sobrecarga gera maior stress, conflito familiar e deterioração das práticas parentais, potenciando situações de maior risco/perigo para as crianças. O confinamento e o encerramento das escolas e de serviços comunitários de apoio às famílias favorecem a sua invisibilidade ao Sistema de Proteção da Criança, o que é evidente no decréscimo de $29.7 \%$ das sinalizaçóes às CPCJ entre janeiro e abril de 2020, comparativamente ao período análogo de 2019.

Pelos motivos apresentados, o cenário é preocupante, especialmente em crianças e famílias já vulneráveis devido, por exemplo, a contextos e processos de exclusão socioeconómica, a dinâmicas abusivas no seio familiar e a necessidades ou condiçôes de saúde especiais. A atuação dos diferentes setores da comunidade (e.g., saúde, educação, proteção) é absolutamente imprescindível para a minimização do impacto da pandemia nas crianças e famílias. Mas como?

\section{ESPECIFICIDADES DA INTERVENÇÃO COMUNITÁRIA EM PERÍODO PANDÉMICO}

\subsection{A intervenção comunitária como prática transformadora}

A intervenção comunitária é uma prática complexa que implica a consideração de múltiplos fatores, desde logo, a própria definição adotada para a ideia de comunidade. Se, por um lado, pode ser definida como um conjunto de indivíduos que, apesar das diferenças que os separam a nível social, cultural e económico, partilham o mesmo território e alguns laços e interesses em comum, implica também ideias de tolerância, reciprocidade, confiança e capacidade de partilhar valores comuns. Assim, apela para 
uma ideia relativamente abstrata de representação da vida social que estabelece limites e descontinuidades artificiais: quem está dentro/fora e o nós/eles (Lillo \& Rosello, 2001). Apesar desta multiplicidade de significações, a comunidade constitui-se como "uma área da vida social que se singulariza pela adesão que mantêm os seus integrantes, com um sentido de pertença que não se entende sem a presença de níveis mínimos de solidariedade e de intercâmbio de significados, características psicológicas e culturais.” (Caride-Gomez, Freitas, \& Callejas, 2007, p. 132). Qualquer projeto de intervenção comunitária tem por base a resolução de problemas concretos, envolvendo a participação da população em todas as etapas - desde a identificação dos problemas às suas soluçóes - procurando, também, dotá-la de recursos próprios que permitam uma abordagem emancipatória da intervenção e não uma intervenção que prolongue a dependência dos seus membros face a serviços e intervenções externas, para lá das necessárias.

O contexto pandémico vivido pela comunidade e, especificamente, pelo território de Guimarães levantou necessidades de intervenção mais complexa que pudesse responder à excecionalidade de um tempo de crianças sem escola e sem espaço público, de famílias sem trabalho e da casa como espaço central da vida de todos/as. A constatação de que seria necessário um reforço de intervenção junto das crianças e suas famílias foi óbvia, desenhando-se um conjunto de possibilidades que permitissem chegar às crianças em casa e às suas famílias. Para este efeito, é fundamental a existência de uma relação entre serviços e comunidades, da relação de proximidade e da alocação dos recursos necessários à satisfação dessas necessidades. As comunidades cumprem importantes funçốes sociais, tais como a socialização e transmissão cultural, a promoção de participação social e integração dos membros do coletivo, a promoção e formação de identidades coletivas, entre outros (Caride-Gomez et al., 2007). Estas funções, no entanto, encontram maiores desafios com processos de confinamento, evidenciando a necessidade de se pensar em estratégias que permitam minimizar os riscos sociais, económicos e individuais resultantes desses processos, quer para as crianças quer para as pessoas adultas. Independentemente do quadro em que se situem as noções de comunidade, há uma premissa fundamental na intervenção comunitária: o conhecimento prévio das suas diferentes componentes é condição central para o sucesso das intervençôes. 
Para esse conhecimento, há um conjunto de elementos que se assumem como particularmente relevantes: o território, a população, as necessidades, os recursos/ presença de organizaçóes sociais e comunitárias, a partilha de interesses comuns, um passado histórico e cultural comum, entre outros de particular relevância (Caride-Gomez et al., 2007). A análise destes elementos permite então o conhecimento aprofundado de uma dada comunidade, de modo a que as intervençôes aí preconizadas correspondam às necessidades identificadas pelos seus membros e pelas diferentes instituições que nela intervenham.

Daremos aqui particular atenção aos seguintes elementos:

Território - nenhum território é neutro, uma vez que ele enforma problemas sociais e equaciona diferentes modos de vida das populações que o habitam. Um mesmo território (re)produz diferentes realidades socioeconómicas, culturais e mesmo educativas. A esse propósito lembramos as conceções de "territórios da pobreza" (Capucha, 2000) ou políticas urbanas de broken windows (Fernandes, 2006), que ajudam a enquadrar a forma como as políticas públicas dirigidas a diferentes comunidades podem potenciar ou mitigar as diferentes vulnerabilidades que apresentem. Assim, o conhecimento do território engloba, entre outros: o espaço geográfico, as configuraçôes (rurais, urbanos, semiurbanos...), as redes de transporte e acessibilidades, os locais de reunião da população as estruturas sociais, educativas e de saúde, à disposição dos seus membros. Espaço e tempo assumem-se como condições fundamentais da existência humana e consubstanciam a relação indivíduo-sociedade, sempre construída numa relação específica entre espaço e tempo. "O cruzamento entre o encontro e o confronto fazem com que o território passe a ser uma realidade viva, não somente da explosão das contradições sendo também de resolução, tanto pelo crescimento de consciência cidadã, como pela renovação do Estado e seus organismos, que hoje têm novas funções e potencialidades de intervenção, entre elas, a intervenção social.” (Marchioni, 2004, p.71). Esta realidade viva do território permite, finalmente, analisar as suas potencialidades e vulnerabilidades na construção das vidas das pessoas que os habitam.

Em período de confinamento torna-se expectável que as vulnerabilidades já existentes no território se agravem e novas surjam, sendo necessário acelerar esse processo de reconhecimento e o desenho de intervenções eficazes. 
População - corresponde ao conjunto de membros de uma comunidade, entre os quais se produzem inter-relaçóes, interesses e valores comuns que criam sentimentos de pertença (Lillo \& Roselló, 2001). As populaçôes de uma dada comunidade são concretas, e torna-se necessário conhecê-las em diferentes dimensões: demográficas, socioeconómicas, profissionais, familiares... Mas, também, nas dimensóes socio-antropológicas, culturais e simbólicas. Aqui podem analisar-se, por exemplo os grupos (formais e não formais, obrigatórios e não obrigatórios, espontâneos e não espontâneos...); as coletividades (representa a população total de uma comunidade); as familias (tipos de famílias, predominâncias, etc.); a evolução da população, as taxas de pobreza, os niveis de bem-estar e a qualidade de vida, os niveis de habilitaçôes literárias das populações, etc. É deste conhecimento aprofundado das populações e sua relação com o território, que a fundamentação das propostas e desenho de políticas locais de intervenção deverá partir.

Necessidades - as necessidades assumem uma dimensão complexa e não simplista na intervenção numa comunidade. Para tal, é necessário identificar as necessidades percecionadas como tal pela própria comunidade e possiveis formas de as suprimir - participação ativa das comunidades, através do aumento de recursos disponíveis, por exemplo, ou de uma distribuição mais equitativa dos mesmos. Da mesma forma, não se trata de identificar somente as já existentes, mas projetar as de médio e longo prazo. Novamente, o período de confinamento de crianças e famílias permitiu identificar necessidades imediatas, como: manutenção da escola em casa, através do fornecimento de equipamento às famílias; apoio alimentar às crianças, pela ausência do suporte escolar e apoio financeiro às famílias com cortes substanciais de salário. No entanto, houve também a possibilidade de começar a desenhar necessidades a médio prazo, para lá destas: o apoio a pais/cuidadores/as ao nível da saúde mental, a construção de modelos de intervenção social integradores e inovadores, a construção de atividades de educação não formal (dada a ausência de projetos no período de pandemia), entre outros.

Importa sublinhar, de qualquer modo, que a intervenção comunitária não deverá reduzir-se à mera supressão de necessidades: ela deve potenciar o desenvolvimento de comunidades, sendo sobretudo, um modo de "organizar relaçôes com maior liberdade e autonomia; permitir uma eleição mais pessoal das atividades e das relaçôes, dar 'vida', 
reconhecendo a existência de um sujeito autónomo que participe no desenvolvimento do mundo ao qual pertence (...)" (Besnard, 1996, p.19). Promove, por isso, uma intervenção onde os grupos se assumem como componente ativa, participante e protagonista, acreditando-se que apenas será efetiva quando exista participação e colaboração por parte dos/as seus/suas destinatários/as. Assim, centra-se em lógicas participativas e mobilizadoras da capacidade dos/as cidadãos/ãs para a mudança; mobiliza diferentes metodologias, endógenas, sociais e educativas que permitam reconhecer a singularidade das comunidades, as suas proximidades e tensóes e a sua heterogeneidade e mobilizam-se para exercícios centrados na cidadania ativa, multicultural e participativa. As abordagens centradas nas pessoas constituem-se então como ação política - exercício de poder para influenciar sistemas políticos, práticas e atitudes. As mudanças nas políticas devem acompanhar-se de organizações de defesa dos mais desiguais e que possam promover solidariedade. É, pois, fundamental o reconhecimento das comunidades como contexto das suas próprias iniciativas, o que implica a adaptação a um território e coletivo humano específicos, com identidades coletivas específicas. Trata-se de um processo de cumplicidade social, onde não se desenha o desenvolvimento para as pessoas, mas sim, com as pessoas, procurando a melhoria das condiçóes de vida, aproveitando os recursos existentes e alargando-os a novas redes de solidariedade social de modo a satisfazer as diferentes necessidades percecionadas pelas próprias comunidades. Como observam André e Abreu (2006), a eventual resolução das formas mais graves de exclusão só será possível se se encontrarem formas inovadoras de revelar necessidades, de cooperar e de democratizar a gestão pública.

No entanto, são conhecidos os grupos sociais e etários com maiores vulnerabilidades, nomeadamente os que se encontram em maior risco de pobreza. O contexto de pandemia reforçou fortemente essas vulnerabilidades e criou "novos" grupos suscetíveis de pobreza e, por isso, com necessidade de apoio institucional. Prevendo-se que os efeitos socioeconómicos destes grupos permaneçam a médio prazo, estes modelos integradores e inovadores de intervenção social deverão ser capazes de identificar esses grupos e, com eles, encontrar as soluçôes mais adequadas com os recursos disponíveis. Também aqui, reconhecer a diversidade e heterogeneidade dos grupos em risco/situação de vulnerabilidade contribui para aumentar a eficácia e pertinência dos modelos de intervenção desenhados. 
Uma das condiçốes de sucesso em intervenção comunitária prende-se com a realização de diagnósticos sociais participativos e uma forte mobilização dos trabalhos em rede. "As parcerias ou redes sociais de parceiros são estruturas de ação integrada que póem em comum recursos com vista a atingir determinadas finalidades, como partilhar pertenças, fazer circular informação, produzir ajudas, mobilizar capital social, ligar os agentes económicos ou controlar as políticas públicas.” (Hespanha, 2008, p. 8-9). No entanto, e apesar das vantagens facilmente reconhecidas, Hespanha identifica dificuldades: legitimidade de intervenção (poder local/político versus instituições de terreno); cooperação institucional; participação e responsabilização; recursos e participação dos cidadãos. Finalmente, deverá ser tido em conta o risco da individualização das medidas.

O modelo de intervenção agora desenhado, em particular atendendo à complexidade do momento socio-histórico em que nos encontramos, orienta-se pelos princípios enunciados e mobiliza os seus quadros de ação e metodologias de intervenção que sustentem o médio e longo prazo, centrando-se na multiplicidade de necessidades identificadas e na inovação da intervenção. O momento que vivemos implica aprender a trabalhar em complexidade, procurando o sucesso para os desafios que se possam colocar no futuro (Nissen, 2020). Pensar criativa e criticamente os papéis dos/as profissionais das diferentes áreas de intervenção, preparando-os/as para diferentes cenários designados de crise, torna-se imperativo. O ProChild CoLAB, em conjunto com a Câmara Municipal de Guimarães, definiu esta questão como a necessidade central da sua atuação em tempos de pandemia, nomeadamente na criação da figura do gestor de crise, com formação específica para atender a essa complexidade e incerteza na intervenção, refletindo sobre as particularidades dos seus territórios e das pessoas e grupos que os compõem. E de que forma poderá a intervenção comunitária responder aos desafios trazidos pela pandemia COVID-19?

\subsection{Especificidades da intervenção comunitária em periodo de crise pandémica}

Face aos novos desafios trazidos pela pandemia foi necessário conceber a intervenção comunitária no âmbito de um modelo integrativo assente numa abordagem colaborativa, intersectorial e multinível à luz das orientaçôes da intervenção em crise e 
informada pelo trauma, por forma a responder às necessidades das famílias e das crianças, no que respeita à saúde física e mental, à proteção e à educação.

Um programa, um sistema ou uma organização que é informada pelo trauma: (1) reconhece o impacto generalizado do trauma e as possíveis trajetórias para a recuperação; (2) reconhece sinais e sintomas nos indivíduos, famílias, profissionais e noutros/as envolvidos/as; (3) responde integrando conhecimento sobre políticas, procedimentos e práticas e (4) procura resistir ativamente à retraumatização (Samhsa, 2014).

A abordagem informada pelo trauma baseia-se no conhecimento sobre o impacto dos acontecimentos potencialmente traumáticos em múltiplos domínios e ao longo da vida. É uma abordagem compreensiva e multinível, na medida em que reconhece o impacto destes acontecimentos: (1) no indivíduo, manifestando-se nas suas atitudes ou nos seus comportamentos; (2) nas relações, por exemplo, no sistema familiar ou na relação entre pares; (3) nas organizaçóes, como a escola e (4) nas comunidades (Matlin et al., 2019; Tebes. Champine, Matlin, \& Strambler, 2019). Em particular, a adoção desta abordagem possibilita o reconhecimento do potencial traumático trazido pela crise pandémica no desenvolvimento e organização de respostas comunitárias com reflexo a diferentes níveis (individual, relacional, organizacional, comunitário), durante e no período pós-pandemia. Para além disso, as ações que integram esta abordagem devem procurar ser específicas para responder no imediato às necessidades trazidas pela crise/ acontecimento traumático, mas também deverão ser suficientemente flexíveis para permitir a adaptação do indivíduo a novos stressores que possam surgir (Tebes et al., 2019). Esta é, por isso, uma abordagem que antecipa resultados a curto, médio e longo prazo.

Do ponto de vista comunitário, torna-se essencial conjugar esforços de diferentes atores sociais e setores da comunidade para desenvolver respostas coordenadas e integradas para responder à crise, indo ao encontro das necessidades no imediato e para promover a resiliência, fazendo frente às consequências vindouras e à possibilidade de novas crises. É precisamente este o racional subjacente à concetualização das comunidades informadas pelo trauma (Matlin et al., 2019), que inspirou a proposta de modelo de intervenção comunitária de resposta à crise pandémica. Com o objetivo de desenvolver comunidades resilientes, as comunidades informadas pelo trauma procuram: 1) capacitar para a identificação precoce de risco psicossocial no sentido da promoção 
da resiliência; 2) estabelecer redes intersectoriais e integradas de serviços e respostas; 3 ) partilhar informação e recursos comunitários e 4) difundir e incorporar princípios de uma abordagem informada pelo trauma nos serviços e políticas (Samhsa, 2014).

É importante salientar que o modelo defendido por Matlin et al. (2019 para as comunidades informadas pelo trauma, que tem como proposta preparar as comunidades para responder às experiências adversas na infância (e.g., maus-tratos) e promover a sua resiliência, integra uma perspetiva de saúde das populaçôes como complementar às práticas clínicas informadas pelo trauma. Ou seja, para além de uma perspetiva clínica focada na redução de sintomas e da perturbação causada pelo trauma, acresce a prevenção do risco psicossocial, a promoção da saúde e o desenvolvimento de políticas públicas. Nesta abordagem, o foco das respostas desloca-se das causas individuais da exposição ao trauma para os determinantes macrossociais da saúde, tais como a carência alimentar, o desemprego, a violência comunitária, as condições de habitação deficitárias, entre outras (Tebes et al., 2019).

Um corolário desta perspetiva da saúde das populações aplicada a acontecimentos com potencial traumático, como é o caso da pandemia COVID-19, é a noção de que há desigualdades sociais na base da distribuição dos casos da doença. A perspetiva de saúde das populações direciona a atenção para essas desigualdades, uma vez que ao reduzi-las está a promover a saúde da população em geral.

A proposta de Matlin et al. (2019) integra os princípios subjacentes à ciência da saúde das populaçóes com aqueles que fundamentam a abordagem focada no trauma, daqui derivando um modelo tridimensional que deverá sustentar o fortalecimento das comunidades face à adversidade, como é o caso da atual crise pandémica. Este modelo tridimensional, representado na figura 2, consiste em três componentes:

(1) uma abordagem que combina a prevenção do risco e a promoção da saúde com intervençốes intencionalizadas para o tratamento, que deverá ser operacionalizada através de uma intervenção concertada e colaborativa entre os serviços da comunidade. Deve integrar intervenções mais abrangentes de promoção do bem-estar, implementadas independentemente da ocorrência da experiência potencialmente traumática/crise e respostas clínicas altamente 
especializadas direcionadas para a redução da sintomatologia decorrente da experiência traumática;

(2) uma estratégica socio-ecológica que opera ao nível individual, relacional, organizacional e comunitário;

(3) intervençôes focalizadas no trauma para as pessoas com sintomatologia traumática e universais para todos os indivíduos num contexto ou população, por exemplo, uma escola, um agrupamento de escolas, uma organização, uma comunidade ou um concelho.

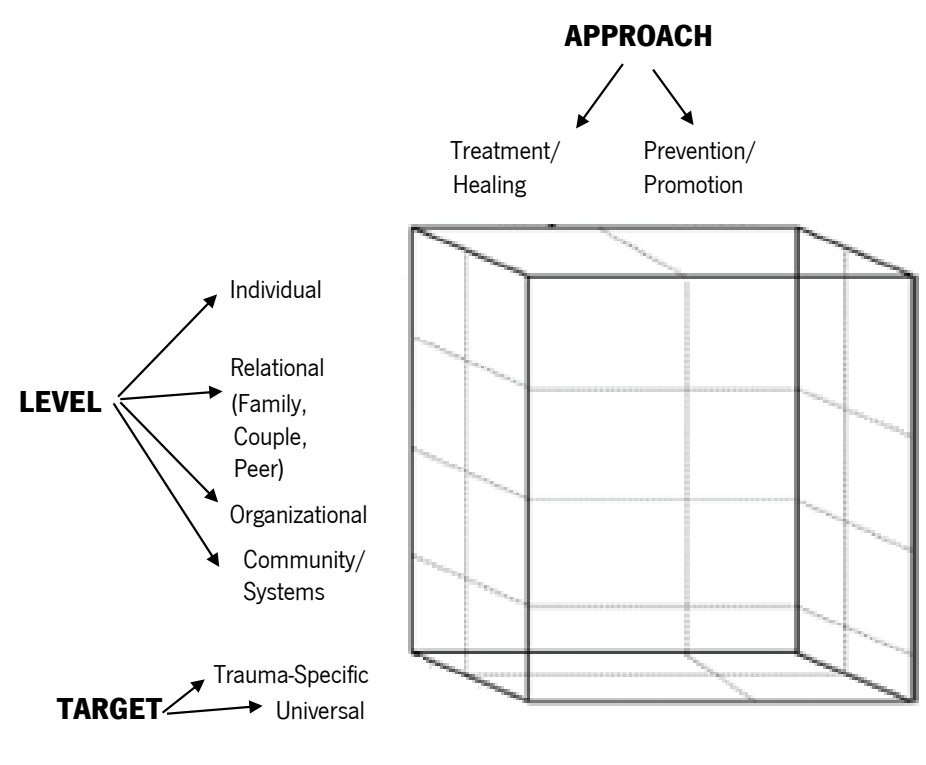

Figura 2. Modelo tridimensional da saúde das populações aplicado às práticas informadas pelo trauma (retirado de Matlin et al., 2019, p.4)

Tebes et al. (2019) sugerem que este modelo tridimensional está alinhado com uma estratégica combinada de prevenção dos riscos e de promoção da saúde da população, o que ajuda a operacionalizar o próprio modelo. Importa considerar que uma abordagem híbrida deverá combinar estratégias universais, seletivas e indicadas, num continuum de intervenção, por forma a potenciar o impacto na saúde da população e os benefícios de cada ação. Como se traduzem estes princípios na intervenção em Guimarães, no âmbito do ProChild Collaborative Action Against COVID-19? 


\section{AÇÃO COLABORATIVA PROCHILD CONTRA A COVID-19}

É baseado nos princípios elencados ao longo deste documento que o ProChild CoLAB tem vindo a desenvolver, em articulação com o Município de Guimarães, projetos de intervenção comunitária que têm por objetivo promover o bem-estar e a resiliência das crianças durante e após o período de pandemia COVID-19. Para tal, tem contado com a mobilização da rede social de emergência do município e da sua articulação com os profissionais dos setores da educação, saúde e proteção das crianças. As intervenções implementadas visam o reforço e a reorganização dos recursos existentes no sentido de uma intervenção comunitária multinível que se baseia em estratégias universais, seletivas e indicadas que serão adequadas às necessidades evidenciadas pelas crianças e famílias, tal como indicado na Figura 3. Serão apresentadas em seguida, cada uma destas estratégias.

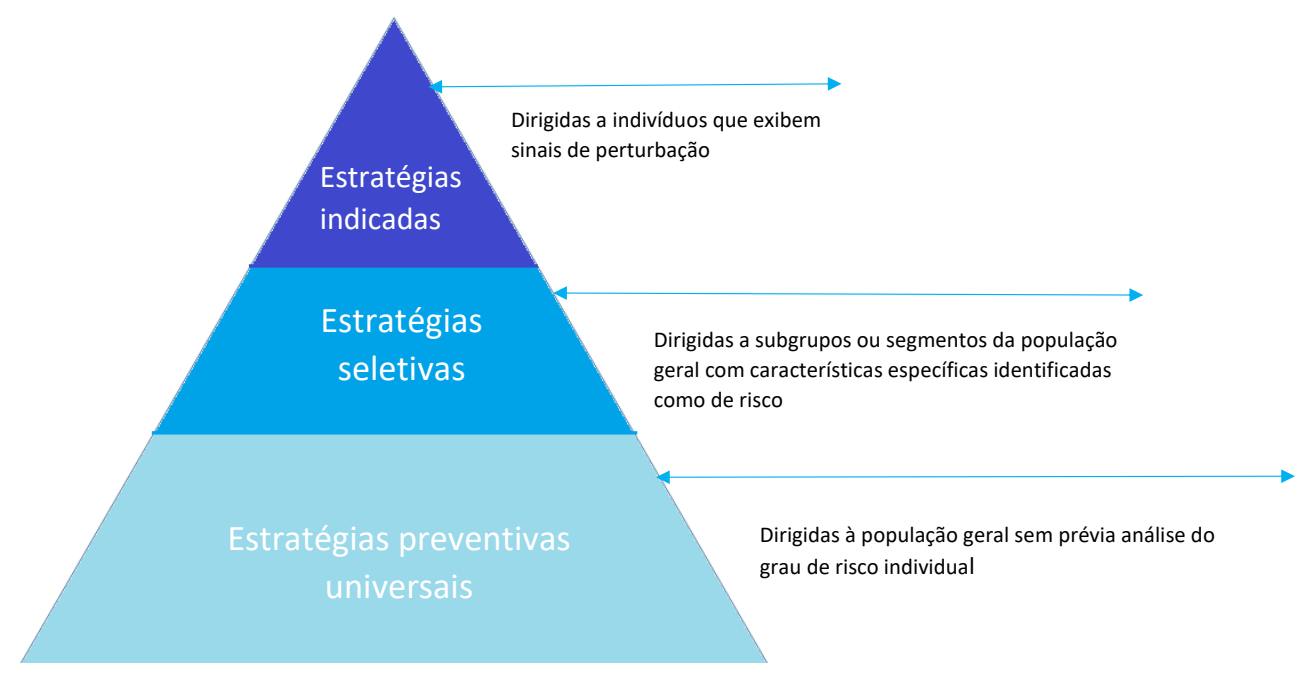

Figura 3. Definição de estratégias universais, seletivas e indicadas.

\section{Estratégias universais}

\section{Apoio às creches}

$\mathrm{Na}$ reabertura das creches e jardins de infância, após o período de confinamento imposto pela pandemia, considerou-se importante disponibilizar um documento de apoio aos/às profissionais de educação de infância, no sentido de contribuir para 
um retomar positivo e tranquilo das crianças, famílias e profissionais a estes contextos. O documento intitulado "Redescobrir a qualidade em educação de infância em tempos de mudança", salienta dimensões promotoras do bem-estar de todos na reativação destas respostas educativas, alinhando-se com as orientações publicadas pela Direção-Geral da Saúde, a 13 de maio de 2020, no âmbito da reabertura das creches. Procurou-se adotar uma visão construtiva, flexível e positiva face às exigências que a situação de pandemia impõe, sem se perder o foco em torno de aspetos considerados essenciais para a promoção do desenvolvimento e aprendizagem da criança: (i) comunicação com as famílias; (ii) autocuidado dos/as profissionais e trabalho colaborativo; (iii) promoção de relações interpessoais; (iv) abordagem pedagógica e organização do ambiente educativo e (v) articulação e cooperação intersectorial. Em cada temática, pretendeu-se suscitar a reflexão dos/as profissionais de educação de infância, formulando-se questóes que apontam para possíveis formas de atuação face às problemáticas identificadas (e.g., "Em tempos de pandemia COVID-19 é necessário reduzir o número de crianças por sala. Como é que podemos tirar partido da redução do número de crianças? $\mathrm{Na}$ organização dos grupos, atendemos às características, preferências e competências de cada criança?”). Desta forma, destacou-se a pluralidade de alternativas para superar os desafios da pandemia e cumprir as orientações da Direção-Geral da Saúde, respeitando-se as especificidades de cada contexto.

Através deste documento, reconhece-se o papel fundamental que os/as profissionais de educação de infância desempenham na vida das crianças e as múltiplas competências (e.g., flexibilidade, criatividade, trabalho de equipa) que apresentam face a períodos de maior desafio e imprevisibilidade.

O documento foi disponibilizado no site do ProChild CoLAB e divulgado nas suas redes sociais. Paralelamente, foi enviado para todas as creches e jardins de infância do município de Guimarães através dos serviços da Câmara Municipal. Junto das creches de Pevidém, envolvidas no projeto "Desenvolvimento e Educação em Creche” do ProChild CoLAB, expressou-se também a disponibilidade da equipa para apoiar diretamente os/as profissionais destas instituiçôes na superação de dificuldades decorrentes da situação de pandemia. 


\section{ProChild Kit(e)}

Como dissemos anteriormente, com o afastamento das crianças das escolas e do espaço público, tornou-se clara a necessidade de desenvolver um projeto de intervenção multidisciplinar direcionado a crianças do 1o ciclo do ensino básico, no sentido de minimizar os efeitos da pandemia COVID-19 no dia-a-dia das crianças, considerando as mudanças profundas e repentinas que se fizeram sentir nos modos de interação e no isolamento em relação aos pares e aos adultos de referência.

Neste sentido, considerou-se que através da educação não formal e, consequentemente, através da ação dos professores de Atividades de Enriquecimento Curricular $(\mathrm{AEC})$, seria o meio mais eficaz de se chegar às crianças e de se encontrarem respostas que contrariassem os efeitos da pandemia COVID-19 no dia a dia das crianças.

O Kit(e) - Kids Transforming Education - é composto por um conjunto de estratégias e ferramentas educativas para professores/as, estruturadas por temas, pretendendo contribuir para a concretização dos seguintes objetivos específicos: criar/ trabalhar/concretizar oportunidades de desenvolvimento de competências múltiplas nas crianças; identificar, apoiar e encaminhar crianças que experienciassem dificuldades emocionais e comportamentais, fornecendo conhecimentos e estratégias úteis aos professores para atuar nestas situaçôes; criar oportunidades de formação para professores/as das AEC sobre competências socio-emocionais e acompanhamento das crianças em situação de pandemia.

O Kit(e) envolveu diretamente 46 professores AEC, das áreas da atividade física e desportiva e das artes performativas, a trabalhar com diferentes escolas do 1o ciclo do ensino básico do município no âmbito dos projetos desenvolvidos pelas cooperativas municipais "A Oficina” e a "Tempo Livre” e um conjunto de turmas, cuja seleção foi feita pelos próprios professores, atendendo ao conhecimento existente sobre as crianças e aos objetivos do projeto.

Foram construídas 3 propostas de atividades a serem desenvolvidas e dinamizadas pelos professores, à distância com os seus alunos. Estas atividades tinham como pano de fundo a Casa como contexto de vida das crianças. Desenvolveram-se, para tal, 
várias sessóes de trabalho com os professores, de apoio às atividades a realizar com as crianças, formação sobre temáticas específicas como a identificação e acompanhamento de crianças que experienciem dificuldades emocionais e ainda formação nas tutorias emocionais.

A par destas sessóes, recorreu-se à Plataforma +Cidadania e a partir das suas funcionalidades criou-se um espaço de comunicação virtual direta entre os professores AEC e as crianças, bem como se criaram fóruns de discussão para promover a reflexão dos professores sobre a importância do brincar e do papel do adulto nesse processo e um banco de recursos, para que os professores pudessem consultar para atividades que desejassem desenvolver no futuro.

Com o ProChild Kit(e) foi possível atingir os objetivos propostos, nomeadamente a redução do afastamento das crianças do espaço escolar, ainda que efetuado virtualmente e o desenvolvimento de competências dos professores AEC, nomeadamente no acompanhamento das crianças e na aprendizagem de estratégias educativas inovadoras no âmbito da educação não-formal.

\section{Estratégias seletivas}

\section{Gestores ProChild para a infância}

No âmbito da intervenção em crise na infância, uma das estratégias implementadas foi a constituição e capacitação de um grupo de profissionais do setor da educação -Gestores ProChild para a Infância. Estes/as gestores/as de crise constituíram-se como figuras de referência num trabalho de mediação e proximidade junto das crianças e respetivas famílias e em estreita articulação com as respostas municipais e da comunidade. A atuação destes profissionais de primeira linha teve por objetivo a mitigação dos efeitos da pandemia e do confinamento na saúde e bem-estar das crianças, sobretudo nos casos de maior vulnerabilidade social. As suas funçóes passaram por: 1) estabelecer uma relação de apoio, restabelecer a segurança, garantindo o conforto físico e emocional de crianças e famílias; 2) ajudar a identificar as suas preocupaçôes e necessidades imediatas; 3) oferecer apoio prático e dar informaçôes úteis; 4) (re)estabelecer o 
contacto das pessoas com a sua rede de apoio social; 5) articular as respostas da comunidade face às necessidades identificadas.

O modelo de trabalho do ProChild CoLAB junto destes gestores incluiu um plano de formação para a definição de um perfil consistente de competências de comunicação, de apoio e de gestão de crise, bem como o acompanhamento e a supervisão do trabalho dos/as gestores. Este modelo foi implementado entre abril e julho de 2020, tendo sido realizadas oito sessões de acompanhamento, formação e supervisão do trabalho dos/as gestores, realizadas via videoconferência. Estas sessões permitiram:

1. identificar temáticas relevantes para a atuação dos/as gestores e desenvolver competências associadas através da formação e da disponibilização de materiais de apoio para o efeito (e.g., autocuidado para profissionais de primeira linha, comunicação com as crianças em contexto ou situação de crise, identificação e avaliação dos riscos psicossociais nas crianças em período pandémico);

2. monitorizar os casos acompanhados pelos/as gestores/as através de uma ficha de monitorização de caso. Os dados obtidos a partir desta ficha de monitorização foram compilados em relatórios periódicos e alvo de análise e discussão pelo grupo, em cada sessão;

3. supervisionar a atuação e as práticas dos/as gestores/as através da apresentação e discussão de casos concretos, partilhados na sessão pelas suas particularidades, complexidade ou especial gravidade;

4. Promover a articulação com outras entidades (e.g., gestores do território, agrupamentos de escolas, CPCJ), estabelecendo-se canais de comunicação direta entre entidades e serviços que possibilitaram a implementação de respostas integradas.

Os 12 gestores/as para a infância atenderam 107 casos durante a primeira fase de implementação deste modelo. As prioridades de intervenção acompanharam a evolução da pandemia e das medidas de contingência aplicadas. Numa primeira fase, priorizaram-se respostas de primeira necessidade, nomeadamente de apoio à habitação, à alimentação e despesas da casa e à aquisição de bens de primeira necessidade (e.g., vestuário, calçado, óculos). $\mathrm{Na}$ fase pós-confinamento, com a reabertura das creches e 
jardins de infância, surgiram com mais frequência necessidades de acompanhamento da situação familiar, encaminhamento para ATL e de apoio psicológico. No que respeita às áreas críticas de intervenção identificadas no acompanhamento de pessoas adultas, destacaram-se as preocupaçóes com a doença (COVID-19) e com a vida após a pandemia, bem como as perdas de recursos. Foram também críticos os sinais de perturbação emocional tanto nas pessoas adultas como nas crianças, sendo que foi esta a área que mais se destacou como de particular importância no apoio às crianças.

\section{Estratégias indicadas}

Com a finalidade de providenciar estratégias indicadas à resolução dos problemas de saúde mental relacionados com a pandemia nas crianças do município de Guimarães, foi desenvolvido e está atualmente em curso um projeto de investigação-ação que inclui um estudo clínico com o objetivo estudar a efetividade dos procedimentos de rastreio, avaliação e intervenção psicológica indicados, especificamente delineados considerando os efeitos da pandemia na saúde mental das crianças dos 3 aos 10 anos de idade e respetivas famílias, e suscetíveis de serem replicados noutros contextos comunitários.

Desta forma, a participação dos agentes comunitários necessários à realização desta iniciativa foi ativada, nomeadamente a Câmara Municipal de Guimarães, o ProChild CoLAB, o Centro de Investigação em Psicologia da Universidade do Minho (CIPsi) e a Associação de Psicologia da Universidade do Minho (APsi-UMinho). As estratégias indicadas integram-se de forma sequencial e consistem em:

1. Rastreio de problemas ou perturbação psicológica nas crianças com idades compreendidas entre os 3 e os 10 anos do ensino pré-escolar e primeiro ciclo da rede pública do Município de Guimarães, tal como reportados pelos/as encarregados/as de educação (e titulares das responsabilidades parentais) em questionários preenchidos na plataforma ProChild integrada com a plataforma +Cidadania (https://maiscidadania.cim-ave.pt/).

2. Avaliação psicológica das crianças que pontuam acima do ponto de corte no rastreio, a qual é realizada com base nas respostas dos/as encarregados/as de educação (e titulares das responsabilidades parentais) a questionários preenchidos na 
plataforma ProChild e numa entrevista clínica dirigida, para validação da presença de problemas ou perturbação psicológica nas crianças relacionadas com a pandemia.

3. Intervenção psicológica indicada junto de crianças com problemas ou perturbação psicológica relacionadas com a pandemia, e respetivas famílias. O protocolo de intervenção integra uma intervenção psicológica de banda larga com estratégias indicadas, direcionada a crianças com problemas ou perturbação psicológica decorrentes da pandemia COVID-19 (e.g., Riegler et al., 2020), bem como uma psicoterapia dirigida com estratégias indicadas para remediar as perturbações psicológicas que já foram associadas na literatura à pandemia COVID-19 (Lucassen et al., 2015), que poderá ou não ocorrer dependendo da (in)eficácia da intervenção psicológica de banda larga. A intervenção psicológica disponibilizada é adaptada à idade da criança, com protocolos distintos para as crianças em idade pré-escolar ou escolar.

Este projeto, com início previsto em outubro de 2020 e término em junho de 2021, conta com a colaboração de diferentes entidades com o objetivo de dar resposta a todas as fases deste projeto. As entidades promotoras são as seguintes: Câmara Municipal de Guimarães; Centro de Investigação em Psicologia da Universidade do Minho (CIPsi); Associação de Psicologia da Universidade do Minho (APsi-UMinho); ProChild CoLAB Against Poverty and Social Exclusion. As entidades parceiras são as seguintes: Centro de Estudos Sociais da Universidade de Coimbra; Centro de Investigação do Núcleo de Estudos e Intervenção Cognitivo-Comportamental (CINEICC) da Universidade de Coimbra; Faculdade de Psicologia da Universidade de Lisboa; Faculdade de Psicologia e Ciências da Educação da Universidade do Porto; Instituto de Saúde Pública da Universidade do Porto. De referir ainda o apoio das seguintes entidades: Centro de Medicina Digital P5, Escola de Medicina, da Universidade do Minho; Agrupamento de Centros de Saúde do Alto Ave, integrado na Administração Regional de Saúde do Norte, IP; Hospital da Senhora da Oliveira Guimarães, E.P.E. 


\section{CONCLUSÃO}

O futuro apresenta-se, tal como o presente, complexo e incerto. Sabemos, já, que as consequências da crise pandémica não são iguais para todos/as e que agudizam vulnerabilidades previamente existentes, nomeadamente as de natureza mais estrutural (Caldas, Silva, \& Cantante, 2020). Paralelamente, grupos até aqui com condições de existência relativamente estáveis necessitam de apoio de diferentes instituições para poderem organizar as vidas pessoais e familiares em período de crise aguda pós-COVID-19. A preparação de modelos integradores e inovadores, que atendam a essas características, parece ser crucial neste momento.

A intervenção local e de proximidade, tem vindo a demonstrar ser absolutamente crucial. O modelo colocado em prática em Guimarães é um dos caminhos possíveis para a intervenção. O facto de ser baseado no conhecimento científico e de atribuir grande protagonismo aos/às agentes sociais, educadores/as, cuidadores/ as, atores/atrizes do trabalho social, potenciando a sua formação no terreno e acompanhando os seus esforços e desempenhos é, certamente, um dos seus atributos distintivos. Mas não é de menor importância a centralização na criança e na família, a análise cuidadosa das suas condiçôes de existência, das suas perceçôes e das suas emoções, bem como o foco contínuo na preocupação em promover o desenvolvimento e o bem-estar, em particular nos contextos marcados pela pobreza e a exclusão. Esta intervenção social, assente no conhecimento existente, é também uma fonte para novo conhecimento e ganha todo o sentido no âmbito de uma ética do cuidado, que corresponsabiliza o poder local, os/as atores/atrizes locais, os serviços públicos, a academia e as instituições do sistema científico nacional.

A intervenção realizada em Guimarães põe também em relevo a importância na definição e concretização das políticas em estreita cooperação com o conhecimento científico. As respostas originais do modelo de intervenção e das suas ações estratégicas - o dispositivo de formação, os/as gestores/as de infância, o ProChild Kit(e), a intervenção na saúde mental - são a consequência do cruzamento de uma vontade política forte de serviço público com a imaginação e o sentido de inovação, solidamente ancorados na investigação e na evidência científica. 
Nesse sentido, o modelo de intervenção face à crise pandémica COVID-19 não se esgota neste tempo de calamidade e de doença, na medida em que possui virtualidades para uma intervenção social promotora do desenvolvimento e do bem-estar da criança no período pós-COVID, não menos ameaçador do que o presente. São hoje mais claros os passos a dar perante estes novos desafios.

\section{REFERÊNCIAS}

Aarons, G. A., Hurlburt, M., \& Horwitz, S. M. (2011). Advancing a conceptual model of evidence-based practice implementation in public service sectors. Administration and Policy in Mental Health and Mental Health Services Research, 38(1), 4-23. https://doi.org/doi:10.1007/s10488-010-0327-7.

Alliance for Child Protection in Humanitarian Action. (2019). Technical note: Protection of children during the Coronavirus pandemic, version 1. https://alliancecpha.org/en/system/tdf/library/attachments/the_alliance_ COVID 19 brief version 1.pdf?file=1\&type=node\&id=37184.

André, I., \& Abreu, A. (2006). Dimensões e espaços da inovação social. Finisterra, 81, 121-141.

Bakrania, S., \& Subrahmanian, R. (2020). Impacts of pandemics and epidemics on child protection: Lessons learned from a rapid review in the context of COVID-19. Florence: Office of Research - Innocenti.

Besnard, P. (1996). La Animación Sociocultural, Barcelona, in Paul Harvoi (Dir.), Pour - Pour une politique de la jeunesse et du développement culturel, (no esp.). Paris.

Caldas, J., Silva, A., \& Cantante, F. (2020). As consequências socioeconómicas da COVID-19 e a sua desigual distribuição. Lisboa: Colabor.

Capucha, L. (2000). Territórios da pobreza, onde é preciso voltar. Sociedade e Território, 30, 8-15.

Caride-Gomez, J.A., Freitas, O. M., \& Callejas, G. V. (2007). Educaşão e desenvolvimento comunitário local. Perspectivas pedagógicas e sociais da sustentabilidade. Porto: ProfEdições.

Center on Developing Child (s.d.). The IDEAS Impact Framework. https://developingchild.harvard.edu/ innovation-application/innovation-approach/.

Fernandes, L. (2006). O medo à cidade. Actas do Encontro de Intervenção Social: Saberes e Contextos. Porto: Escola Superior de Educação Paula Frassinetti, pp. 99-110.

Hespanha, P. (2008). Políticas sociais: Novas abordagens, novos desafios. Revista de Ciências Sociais, 39(1), 5-15. Horesh, D., \& Brown, A. D. (2020). Traumatic stress in the age of COVID-19: A call to close critical gaps and adapt to new realities. Psychological Trauma: Theory, Research, Practice, and Policy, 12(4), 331. https://doi. org $/ 10.1037 / \operatorname{tra} 0000592$. 
International Commission on the Futures of Education (2020). Education in a post-COVID world: Nine ideas for public action. Paris, UNESCO.

Lillo, N., \& Roselló, E. (2001). Manual para el trabajo social comunitario.Madrid: Nancea.

Liu, j., Bao, Y., Huang, X., Shi, J., \& lu, L. (2020). Mental health considerations for children quarantined because of COVID-19. The Lancet Child \& Adolescent Health, 4(5), 347-349. https://doi.org/10.1016/S2352$\underline{4642(20) 30096-1 .}$.

Lucassen, M. F., Stasiak, K., Crengle, S., Weisz, J. R., Frampton, C. M., Bearman, S. K., ... Kingi, D. (2015). Modular approach to therapy for anxiety, depression, trauma, or conduct problems in outpatient child and adolescent mental health services in New Zealand: Study protocol for a randomized controlled trial. Trials, 16(1), 1-12. https://doi.org/10.1186/s13063-015-0982-9.

Marchioni, M. (2004). Planificacion social y organizacion de la comunidad. Alternativas avazadas a la crisis. Madrid. Editorial Popular.

Matlin, S. L., Champine, R. B., Strambler, M. J., O’Brien, C., Hoffman, E., Whitson, Tebes, J. K. (2019). A community's response to adverse childhood experiences (ACEs): Building a resilient, trauma-informed community. American Journal of Community Psychology, 1-16. https://doi.org/10.1002/ajcp.12386.

Nissen, L. B. (2020). An Open Letter to Social Work Students in the Time of COVID-19: The Future Is Calling. New Social Worker, 27(2), 10-12.

Qiu, J., Shen, B., Zhao, M., Wang, Z., Xie, B., \& Xu, Y. (2020). A nationwide survey of psychological distress among Chinese people in the COVID-19 epidemic: Implications and policy recommendations. General Psychiatry, 33. http://doi.org/10.1136/gpsych-2020-100213.

Reimers, F. \& Schleicher, A. (2020). Schooling disrupted, schooling rethought: How the COVID-19 pandemic is changing education. New York, OECD Press

Reis, J. (2020). Economia do cuidado. In J. Reis (Editor), Palavras para lá da pandemia: Cem lados de uma crise, (p. 54). Coimbra, Centro de Estudos Sociais.

Riegler, J. L., Raj, S. P., Moscato, E. L., Narad, M. E., Kincaid, A., \& Wade, S. L. (2020). Pilot trial of a telepsychotherapy parenting skills intervention for veteran families: Implications for managing parenting stress during COVID-19. Journal of Psychotherapy Integration, 30(2), 290. https://doi.org/10.1037/int0000220.

Rodrigues, F. (2020). Pandemia, desigualdade, pobreza e o papel das políticas públicas. https://areiadosdias. blogspot.com/2020/06/pandemia-desigualdade-e-pobreza.html.

Sistovaris, M., Fallon, B., Miller, S., Birken, C., Denburg, A., Jenkins, J., \& Stewart, S. (2020). Child Welfare and Pandemics. Toronto, Ontario, Policy Bench, Fraser Mustard Institute of Human Development, University of Toronto.

Sprang, G., \& Silman, M. (2013). Posttraumatic stress disorder in parents and youth after health-related disasters. Disaster Medicine and Public Health Preparedness, 7(1), 105-110. https://doi.org/10.1017/dmp.2013.22. 
Substance Abuse and Mental Health Services Administration (SAMHSA, 2014). SAMHSA's Concept of Trauma and Guidance for a Trauma-Informed Approach. HHS Publication No. (SMA) 14-4884. Rockville, MD, Substance Abuse and Mental Health Services Administration.

Tebes, J. K., Champine, R. B.,Matlin, S. L., \& Strambler, M. J. (2019). Population health and trauma-informed practice: Implications for programs, systems, and policies. American Journal of Community Psychology, 1-15. https://doi.org/10.1002/ajcp.12382.

United Nations International Children's Emergency Fund. (UNICEF, 2020). Child Protection Emergency Preparedness and Response Guidance to the COVID-19. New York, UNICEF.

Walsh, C., Reutz, J. R., \& Williams, R. (2015). Selecting and implementing evidence-based practices: A guide for child and family serving systems. http://www.culpeperjdr.com/resources/ImplementationGuide-Apr2015onlinelinked.pdf.

Wang, G., Zhang, y., Zhao, J., \& Zhang, J. (2020). Mitigate the effects of home confinement on children during the COVID-19 outbreak. The Lancet Child \& Adolescent Health, 395(10228), 945-947. https://doi.org/10.1016/S0140-6736(20)30547-X. 